\title{
Article
}

\section{Cross-cultural development and psychometric evaluation of a measure to assess fear of childbirth prior to pregnancy}

Stoll, K, Hauck, Y, Downe, S, Edmonds, J, Gross, M, Malott, A, McNiven, P, Swift, E, Thomson, G and Hall, W

Available at http://clok.uclan.ac.uk/14026/

Stoll, K, Hauck, Y, Downe, S ORCID: 0000-0003-2848-2550, Edmonds, J, Gross, M, Malott, A, MCNiven, P, Swift, E, Thomson, G ORCID: 0000-0003-3392-8182 et al (2016) Cross-cultural development and psychometric evaluation of a measure to assess fear of childbirth prior to pregnancy. Sexual and Reproductive Healthcare, 8 . pp. 49-54. ISSN 1877-5756

It is advisable to refer to the publisher's version if you intend to cite from the work. http://dx.doi.org/10.1016/j.srhc.2016.02.004

For more information about UCLan's research in this area go to http://www.uclan.ac.uk/researchgroups/ and search for < name of research Group>.

For information about Research generally at UCLan please go to http://www.uclan.ac.uk/research/

All outputs in CLoK are protected by Intellectual Property Rights law, including Copyright law. Copyright, IPR and Moral Rights for the works on this site are retained by the individual authors and/or other copyright owners. Terms and conditions for use of this material are defined in the policies page. 


\section{Cross-cultural development and psychometric evaluation of a measure to assess fear of childbirth prior to pregnancy}

Stoll K, Hauck Y, Downe S, Edmonds J, Gross MM, Malott A, McNiven P, Swift E, Thomson G and Hall W

Sexual and Reproductive Healthcare.

Background: Assessment of childbirth fear, in advance of pregnancy, and early identification of modifiable factors contributing to fear can inform public health initiatives and/or school-based educational programming for the next generation of maternity care consumers. We developed and evaluated a short fear of birth scale that incorporates the most common dimensions of fear reported by men and women prior to pregnancy, fear of: labour pain, being out of control and unable to cope with labour and birth, complications, and irreversible physical damage.

Methods: University students in six countries (Australia, Canada, England, Germany, Iceland, and the United States, $\mathrm{n}=2240$ ) participated in an online survey to assess their fears and attitudes about birth. We report internal consistency reliability, corrected-itemto-total correlations, factor loadings and convergent and discriminant validity of the new scale.

Results: The Childbirth Fear - Prior to Pregnancy (CFPP) scale showed high internal consistency across samples $(\alpha>0.86)$. All corrected-item-to total correlations exceeded 0.45, supporting the uni-dimensionality of the scale. Construct validity of the CFPP was supported by a high correlation between the new scale and a two-item visual analog scale that measures fear of birth ( $r>0.6$ across samples). Weak correlations of the CFPP with 
scores on measures that assess related psychological states (anxiety, depression and stress) support the discriminant validity of the scale.

Conclusion: The CFPP is a short, reliable and valid measure of childbirth fear among young women and men in six countries who plan to have children.

\section{Highlights}

- Fear of childbirth can precede pregnancy and is associated with preferences for cesarean section among young men and women who plan to have children in the future.

- Assessing fear of birth and associated factors for young adults in different countries is an important first step in understanding why some young women and men are afraid of childbirth and how this issue might be addressed.

- We developed a 10-item fear of birth scale that incorporates the main dimensions of fear reported by young adults in the literature, including fear of: labour pain, bodily damage, and complications.

- $\quad$ The Childbirth Fear - Prior to Pregnancy (CFPP) scale had high internal consistency reliability across samples, measured one underlying construct, was highly correlated with another measure of childbirth fear, and was weakly correlated with measures of depression, anxiety and stress.

\section{Keywords}

Childbirth fear, young adults, survey, cross-cultural, psychometrics, scale 


\section{Background}

Childbirth fear is reported by $2.5 \%-78 \%$ of pregnant women, depending on the instrument used to measure fear and the level of severity (1-5). Severe fear of childbirth affects $2.5 \%$ of nulliparas and $4.5 \%$ of multiparas (6) and is characterized by nightmares, physical complaints, and difficulties concentrating on work or family activities. Common childbirth fears include worries about the health and safety of the baby, and fear of intolerable pain, prolonged labour, an inability to cope with labour and unsupportive hospital staff (5-8).

While numerous studies about women's childbirth fear have been published over the past 5 years, less is known about men's childbirth fear. Male partners have described emotionally challenging experiences with supporting their partners during childbirth, particularly when there were complications, when medical care was deemed to be unsatisfactory and they felt excluded from decision-making (9). Feelings of stress, panic, fear and helplessness are also not uncommon (10). In one study, it was estimated that $13 \%$ of men are fearful of birth (4); another study with 762 Swedish men found that $11 \%$ suffered from childbirth fear (11). A literature review by Hanson et al. (2009) identified the following paternal fears: harm to the mother or newborn baby, partners’ pain, feelings of helplessness (especially when fathers were not involved in decision-making), lack of knowledge, and concern about high-risk interventions. The most common fear reported by fathers was fear that their partner would have to endure intolerable pain and suffering (12).

Partners' childbirth fear and mode of delivery preferences have been linked to birth outcomes. Based on her Swedish study with 1074 pregnant women and their 
partners, Hildingsson (2014) reported that partners' attitudes were important in predicting actual mode of birth (13). Concordance between pregnant women and their partners' cesarean section (CS) preferences resulted in $72.7 \%$ of couples having a planned CS. If a woman preferred a CS, but her partner preferred a vaginal birth, only $42.9 \%$ had a planned CS. Planned CS rates were highest when both parents expressed fear of birth (50\%). These findings indicate that it is important to include men in studies that assess the link between childbirth fear and birth outcomes, so that interventions can be developed that target the dyad, not just the pregnant woman. Likewise, it is beneficial to understand the attitudes and fears of young men and women who plan to have children in the future, to identify and address modifiable factors that might predispose them to fear of childbirth.

Recent studies of young women and men planning to have children indicate that attitudes towards pregnancy and birth are well developed in this population (11-15) and the same positive association between prenatal preferences for elective interventions and fear of childbirth is seen among men and women who plan to have children and pregnant women $(14,15,19)$. These findings suggest that addressing fear of birth during pregnancy might be too late, and earlier intervention is necessary. This could be achieved by developing educational modules for secondary school students that address common fears and misconceptions about pregnancy and birth, are aligned with best practice guidelines for the care of low risk women and contribute to international efforts to reduce rates of elective interventions in high resource countries.

High childbirth fear in the pre-pregnant Canadian population is estimated at 13.6\% among young women and 3.5\% among young men (14). These estimates are based 
on a survey that included a 6-item fear of birth scale and a mixture of open-ended and pre-defined Likert type questions. High fear was defined as scores greater than one standard deviation above the mean and low fear as scores greater than one standard deviation below the mean. Criterion sampling was used to select a subsample of young women with high and low fear of birth $(n=461)(14)$.

Thematic analysis of Canadian women's comments revealed that participants with high fear of birth expressed feeling vulnerable and afraid when thinking about labour and birth, because of the potential for physical damage (e.g., vaginal tearing and stretching) and intolerable pain (14). Young women with high fear tended to describe pregnancy and birth as unpredictable and risky, whereas respondents with low fear regarded these processes as normal and natural. Complications during pregnancy, labour and birth were expected and considered unavoidable by women with high fear. While women in both groups believed labour to be painful, women with low fear expected to be able to manage the pain, whereas women with high fear were frightened by the prospect of pain and concerned about their ability to cope with pain. Some women with high fear expressed fears about panicking and being out of control and not knowing what to do (14).

A subset analysis of male students revealed that $77 \%$ considered birth to be risky and unpredictable and $\sim 40 \%$ were worried about physical changes to the female body as a result of childbirth. Elevated risk perceptions were associated with increased fear of birth among men (15); when asked why young men and women preferred Cesarean section over vaginal birth, $56 \%$ of women and $32 \%$ of men chose CS to avoid labour pain and/or because they are afraid of pain (16). 
This body of literature informed the development of a fear of childbirth measure for young women and men who plan to have children in the future. We report on the development of the new scale, the Childbirth Fear - Prior to Pregnancy (CFPP) scale and report the reliability and validity of the measure in young adults from six countries.

\section{Methods}

Design and Sample: Data were collected in six countries between March 2014 and March 2015, using an online survey. Young men and women who were already parents, experiencing pregnancy at the time of data collection, or did not plan to have children in the future were excluded. Ethics approval was obtained at the institution of the primary author and at participating institutions.

Sample 1 (Australia): At a large university in Western Australia, 8000 domestic students were invited to participate in the survey in March 2014. One reminder email was sent out two weeks after first contact.

Sample 2 (Canada): At a small university in Northern British Columbia the survey was disseminated to all students $(\mathrm{N}=4300)$ in September 2014. Despite reminder e-mails and a draw for a $\$ 250$ gift card, we received only 59 completed responses. To increase the Canadian sample size, we added a mid-sized Ontario university and contacted individual departments and faculties to disseminate the survey to their students in January 2015.

Sample 3 (England): A link to the online survey was posted on a central messaging board on the website of a university in North-West England (total student 
body at the time of posting was 32,499). The link was reposted 6 times between April 2014 and May 2014. Students within the Schools of Health, Social Work, and Psychology were also sent a direct email invitation/link to the survey $(\mathrm{n}=\sim 6,300)$.

Sample 4 (Germany): An invitation to complete the survey was sent to all students at a small medical university in Northern Germany in October/November 2014 $(\mathrm{N}=3130)$. Several reminder e-mails were sent out, to encourage participation.

Sample 5 (Iceland): An e-mail invitation was sent to all students at the largest university in Iceland in early November 2014 (N=9805). A reminder e-mail was sent out one week after first contact.

Sample 6 (USA): An e-mail invitation to complete the online survey was sent to a random sample of 4547 undergraduate students at a private college in the North-eastern United States (50\% of the undergraduate student body) in October 2014. A reminder was sent out one week after the initial invitation.

The Australian university and the American college are located in large urban centres. The German, Icelandic and English university and one of the Canadian universities are located in small/mid-sized urban centres and one Canadian university is located in a semi-rural setting.

As previously noted, we included young men in our cross-cultural sample because men contribute to maternity care decisions and because the feelings and attitudes of fathers (including paternal fear of childbirth) affect women's mode of delivery (13). Survey items were worded in a way that applied to both women and men, e.g. 'Please indicate why you would prefer an epidural (for your partner)? ‘

\section{Development of the instrument}


A review of the literature revealed more than 10 different self-report measures of childbirth fear $(4,5,20-28)$, ranging from 1-item measures $(26,27,29)$ to a 64 -item scale (5). The 33-item Wijma Delivery and Expectancy Questionnaire (WDEQ) (20) is the most commonly employed measure and has been used in several countries (1-3, 30-32).

We considered existing measures unsuitable, because they were targeted to pregnant women and included items that might frighten young women and men (e.g. items about the potential death of the baby or uncontrollable screaming during labour) $(20,28)$. Some of the one or two item scales could have been adapted for use with young adults; we adapted one such scale (24) to test the discriminant validity of our new measure. Nonetheless, we perceived one or two item scales as failing to capture the complexities of childbirth fear among young adults; knowledge of these complexities would be important to develop interventions to reduce childbirth fear.

Our objective was to develop a short measure that captures dimensions of fear that have been reported by young adults who plan to have children in the future, such as fear of labour pain, fear of bodily damage, fear of complications, and fear that harm might come to the baby $(14,15)$. To this end, we developed a 10 -item scale to assess fear of birth among young adults prior to their first pregnancy and birth. The scale was adapted from a 6-item fear of childbirth scale that was validated with Canadian university students and published by the first author and colleagues in 2013 (15). The 6-item scale, created from existing items on the survey, was uni-dimensional and had an acceptable alpha (0.75); however, it included three reverse-scored items that measured confidence in birth, rather than fear of birth. We retained two items from the original scale ('I am worried that labour pain will be very intense’; 'I am afraid that I might panic and not 
know what to do during labour') and changed the wording of one of the original items from ' I am fearful of the labour process' to' I am fearful of birth'. The 6-item scale did not include items about imagined harm to the baby, anticipated complications during pregnancy, and fears about physical damage as a result of pregnancy and birth; those fears were articulated by students in their comments on the survey. We added items that assessed these dimensions of fear. Scale items are listed in Table 1. Response options were as follows: (1) strongly disagree, (2) disagree, (3) somewhat disagree, (4) somewhat agree, (5) agree and (6) strongly agree. Members of the study team and five young women who met the eligibility criteria reviewed the adapted survey and suggested minor revisions.

Translation of the instrument: We used a forward-backward translation process to translate the survey into Icelandic and German. The forward translation of the English instrument into Icelandic and German was completed in the autumn of 2014 by bilingual midwives who were native German and Icelandic speakers. While wording and individual survey questions were minimally adapted for local context (e.g. maternity care provider options and definitions), the structure and content of the original survey was maintained. The Depression, Anxiety and Stress Scale (DASS-21) had already been translated and validated in the Icelandic University population (33) and among German patients with and without chronic pain (34).

The forward translated versions of the survey were translated back into English by bilingual translators whose native language was English and who had not seen the original English survey. This allowed for comparison of the two English versions (i.e. the original and back translated versions) to detect inconsistencies, mistranslations, changes 
in meaning, cultural gaps and/or lost words or phrases (35). The comparison revealed that the versions were similar and only minor changes in wording were made to the final documents. Because the cross-cultural design of the study prevented us from changing the wording of survey items, we did not perform pilot testing of the German and Icelandic survey versions. Icelandic and German students who met eligibility criteria tested the web application of the surveys.

\section{Psychometric assessment}

Internal consistency reliability of the CFPP scale was assessed with Cronbach's alpha. Alphas $>0.7$ were considered acceptable (36). To determine whether all scale items measured one underlying construct, we calculated corrected item-to-total correlations for each item. When all corrected item-to-total correlations exceed 0.45 there is strong evidence of the uni-dimensionality of a scale (37). The factor structure of the CFPP was assessed via unweighted least squares factor analysis (no rotation). We reviewed scree plots, factor loadings and \# of Eigenvalues $>1$ to determine the optimal factor structure of the scale in each country.

An assessment of convergent and discriminant validity is routinely undertaken to support the construct validity of a new measure (38). Convergent validity is achieved when a new scale is highly correlated with a scale that measures the same construct; discriminant validity is supported when the correlational coefficients between a new scale and existing scales that measures different constructs are low. Convergent validity was computed by correlating the CFPP scores with a two-item visual analog scale called the Fear of birth Scale (FOBS), adapted from Haines and colleagues (2011) (24). In the original version, pregnant women are asked to mark two 100 millimetre VAS-scales 
anchored by the words: calm /worried and no fear/strong fear. We re-worded the original question, 'How do you feel right now about the approaching birth? to 'When you think about giving birth (your partner giving birth), how do you feel?' To create a scale score, scores from the two VAS scales are averaged. The original two-item VAS was administered to women in Australia and Sweden (Cronbach's alpha=0.91) and to expectant fathers in Sweden $(24,39)$. We chose this measure because it is a short fear of birth scale that was easily adapted to apply to men and women contemplating pregnancy.

Discriminant validity was assessed by correlating the CFPP scale scores with the DASS-21 subscales (depression -7 items, anxiety-7 items and stress-7 items) (40). Respondents were asked to use 4-point severity/frequency scales to rate the extent to which they have experienced each state over the past week. The normal range was considered 0-7 for the stress subscale, 0-4 for the depression subscale, and 0-3 for the anxiety subscale. The DASS-21 scale had high internal consistency reliability reported in non-clinical samples $(41,42)$.

Correlations between 0.7-0.9 were considered strong, between 0.4-0.6 moderate and between 0.1-0.3 weak. Strong correlations are indicative of convergent validity, weak correlations signal discriminant validity, and moderate correlations can be interpreted as supporting discriminant validity, with some conceptual overlap between the phenomena measured.

\section{Results}

Overall, 2240 completed surveys were received, ranging from 206 in Germany to 654 in Australia (see Table 2 for sample sizes). The majority of respondents were female, ranging from $77.5 \%$ in Australia to $91.1 \%$ in England. The mean age of students ranged 
from 19.6 years (United States) to 23.7 years (Germany). The proportion of students born outside the country was highest in Australia (31.5\%) and lowest in Germany (4.9\%). The US sample had the highest proportion of students who reported their relationship status as single (66.9\%), and Germany the lowest (31.1\%) (see Table 2 for socio-demographic characteristics of samples).

The internal consistency reliability of the CFPP scale was acceptable for each country sample, 0.86 or higher, and was not improved by item deletion (Table 3). Corrected item-to total correlations exceeded 0.48 across samples (Table 1). Factor analysis yielded similar results. In Australia, factor loadings ranged from 0.51-0.71, in Canada from 0.54-0.72, in Germany from 0.56-0.77, in Iceland from 0.53-0.77, in the UK 0.52-0.81 and in the US from 0.51-0.71. These factor loadings are based on a one factor solution. When repeating the analysis without specifying a fixed number of factors, we found that a three-factor solution was also possible. More specifically, items that measure fear of complications loaded on one factor (items 5,7, \& 8); items that measure fear of physical changes following childbirth loaded on one factor (items 9, 10); and items that measure fear of pain and being out of control (items 1,2,3,4, and 6) loaded on one factor.

The two-item visual analog FOBS scale had excellent reliability $(>0.90)$ in the Australian, Canadian, English and American samples and good reliability $(>0.86)$ in the Icelandic and German samples. Furthermore, the FOBS scores were strongly correlated with CFPP scores $(r>0.6$ in the German, Icelandic and American samples and $r>0.7$ in the Australian, Canadian and English samples). The reliability of the DASS-21 was excellent (>0.9) for samples in each country. Internal consistency reliabilities of the subscales exceeded 0.80 for samples in each country, with the exception of the anxiety 
subscale in the Icelandic sample (alpha=0.66). The CFPP scores were significantly, but weakly correlated with the DASS 21 subscale scores across samples. Pearson’s correlational coefficients to assess convergent and discriminant validity of the CFPP with the FOBS and DASS-21 are reported in Table 4.

CFPP scores were highest among English students (38.5), and lowest among German students (29.8). The same pattern was observed for scores on the VAS scale. On average, scores were in the normal range for the stress, anxiety and depression subscales, across samples (Table 5).

\section{Discussion}

The 10-item Childbirth Fear - Prior to Pregnancy (CFPP) scale is a unidimensional scale with good internal consistency reliability across samples from six countries, as well as convergent and discriminant validity, as hypothesized. We prefer to conceptualize the CFPP as a uni-dimensional scale and suggest that researchers who want to use the scale calculate full scale scores, rather than subscale scores, because subscales with fewer than three items are not recommended.

The reliability of the CFPP scale was similar for men and women, with the exception of Iceland. In Iceland, reliability estimates for men were lower than for women, but similar to estimates for men in the other countries in this study. Deletion of any of the 10 CFPP items would not have increased the Cronbach's alpha for Icelandic men. One potential explanation for the discrepancy in reliability estimates might be that compared to Icelandic women, more Icelandic men were single/not in a committed relationship at the time of data collection. The CFPP scores of Icelandic men were also slightly 
negatively skewed; whereas, the scores for Icelandic women were not, which potentially explains the differences in reliability estimates (43).

Depression, anxiety and stress scores were positively but weakly associated with fear scores across samples, a relationship that has also been demonstrated among pregnant women $(2,6,44-46)$. The short version of the Depression-Anxiety Stress Scale was a reliable measure across student samples, adding to a growing body of evidence that supports use of the scale in non-clinical samples $(41,42)$. The internal consistency reliability of the Icelandic version of the DASS-21 subscales was similar to Cronbach's alpha reported by Ingimarsson (2010), i.e. 0.85 for depression, 0.82 for stress and 0.73 for anxiety (33).

American university students consistently showed higher correlations between DASS-21 scores and fear of birth, compared to students from other countries, indicating that fear of birth overlaps more with other negative psychological states among US students. Fear, anxiety, depression and stress scores were lower in the Icelandic and German student samples, compared to other student samples. Variations in fear scores and reasons for these differences across samples will be examined in more detail in a subsequent analysis.

In previous studies, university students' confidence about and access to information about pregnancy and birth was associated with reduced fear of childbirth $(47,48)$. These findings support the development of educational modules that promote pregnancy and birth as normal rather than frightening life events and address specific fears, such as fear of irreversible physical damage and uncontrollable pain. Our findings 
suggest that the CFPP could serve as a useful measure for assessing the effectiveness of such educational programmes.

\section{Strengths and Limitations}

The original sampling frame specified that all students at each institution be invited to participate in the survey; however, it was not approved at all study sites, resulting in sampling variations. In addition, the demographic profile of students differed across samples. On one hand, this supports the reliability and validity of our new scale across socio-demographically diverse populations. On the other hand, it makes interpreting differences in fear scores across samples difficult. In future analyses, we will examine fear scores by gender, country of origin, ethnicity and age.

Country-specific response rates were low, but generally consistent with those of online surveys. The generalizability of our findings to all students at participating institutions is limited by the low response rate. We targeted university students as samples to capitalize on concentrations of high numbers of young adults in singular locations; however, we recognize the limitations of our sample for the generalizability of our findings. Researchers who want to use the CFPP are encouraged to assess reliability and validity of this measure with their target population.

Strengths of the study include the rigorous translation process, the inclusion of men and the ability to assess the psychometrics of the new scale in six independent samples, across three continents. In addition, the refinement and development of the CFPP scale was informed by quantitative and qualitative findings from a large sample of young women and men $(14,15)$ thus enhancing the validity of items added to the scale. 


\section{Conclusion}

We developed a short scale that measures childbirth fear among young men and women prior to pregnancy. The CFPP represents an improvement over the only other fear of birth scale for young adults that has been reported in the literature (15), because the internal constancy reliability is higher, and the psychometric properties of the scale could be replicated across six samples. The scale can be used to identify and address modifiable factors that are linked to the development of childbirth fear among young adults. Further analysis will examine factors that might predispose young adults to have high scores on the CFPP scale across different cultural settings. Future work will also examine potential gender differences in key outcomes and whether cut-off scores might be useful for identifying young adults who would benefit from interventions to reduce childbirth fear. 
Table 1: Corrected item-to-total correlations of CFPP scale items, by sample

\begin{tabular}{|c|c|c|c|c|c|c|c|}
\hline & Item & & & & & & \\
\hline & & AUSTRALIA & CANADA & ENGLAND & GERMANY & ICELAND & $\begin{array}{l}\text { UNITE } \\
\text { STATE }\end{array}$ \\
\hline 1 & I am worried that labour pain will be too intense. & 0.62 & 0.66 & 0.66 & 0.61 & 0.66 & 0.61 \\
\hline 2 & $\begin{array}{l}\text { I feel I (my partner) will not be able to handle the } \\
\text { pain of childbirth. }\end{array}$ & 0.59 & 0.62 & 0.67 & 0.49 & 0.59 & 0.60 \\
\hline 3 & $\begin{array}{l}\text { I am afraid that I (my partner) might panic and not } \\
\text { know what to do during labour \& birth. }\end{array}$ & 0.60 & 0.57 & 0.66 & 0.55 & 0.63 & 0.61 \\
\hline 4 & I am fearful of birth. & 0.65 & 0.66 & 0.74 & 0.70 & 0.71 & 0.65 \\
\hline 5 & I am worried that harm might come to the baby. & 0.58 & 0.63 & 0.49 & 0.55 & 0.51 & 0.48 \\
\hline 6 & $\begin{array}{l}\text { I am afraid that I (my partner) will be out of } \\
\text { control during labour and birth. }\end{array}$ & 0.65 & 0.50 & 0.58 & 0.51 & 0.61 & 0.61 \\
\hline 7 & I fear complications during labour and birth. & 0.60 & 0.58 & 0.51 & 0.67 & 0.67 & 0.56 \\
\hline 8 & Birth is unpredictable and risky & 0.57 & 0.64 & 0.52 & 0.54 & 0.50 & 0.52 \\
\hline 9 & $\begin{array}{l}\text { I am afraid of what the labour and birth process } \\
\text { will do to my (my partner's) body. }\end{array}$ & 0.56 & 0.52 & 0.58 & 0.58 & 0.64 & 0.53 \\
\hline 10 & $\begin{array}{l}\text { I am afraid that my (my partner's) body will never } \\
\text { be the same again after birth. }\end{array}$ & 0.49 & 0.54 & 0.63 & 0.57 & 0.60 & 0.48 \\
\hline
\end{tabular}


Table 2: Socio-demographic characteristics of samples

\begin{tabular}{|l|l|l|l|l|l|l|}
\hline & AUSTRALIA & CANADA & ENGLAND & GERMANY & ICELAND & $\begin{array}{l}\text { UNITED } \\
\text { STATES }\end{array}$ \\
\hline $\begin{array}{l}\text { Included in } \\
\text { analysis }\end{array}$ & 654 & 239 & 303 & 206 & 460 & 378 \\
\hline Female n (\%) & $507(77.5)$ & $191(79.9)$ & $276(91.1)$ & $172(83.5)$ & $411(89.3)$ & $311(82.3)$ \\
\hline $\begin{array}{l}\text { Male n (\%) } \\
147(22.5)\end{array}$ & $48(20.1)$ & $27(8.9)$ & $34(16.5)$ & $49(10.7)$ & $67(17.7)$ \\
\hline $\begin{array}{l}\text { Age (mean, } \\
\text { SD) }\end{array}$ & $22.3(4.7)$ & $22.5(3.8)$ & $22.8(4.1)$ & $23.7(3.4)$ & $23.1(3.5)$ & $19.6(1.2)$ \\
\hline $\begin{array}{l}\text { Born outside } \\
\text { country } \\
\text { n (\%) }\end{array}$ & $206(31.5)$ & $46(19.2)$ & $32(10.6)$ & $10(4.9)$ & $36(7.8)$ & $45(11.9)$ \\
\hline $\begin{array}{l}\text { Relationship } \\
\text { status: Single } \\
\mathrm{n} \text { (\%) }\end{array}$ & $293(44.8)$ & $101(42.3)$ & $93(30.7)$ & $64(31.1)$ & $177(38.5)$ & $267(70.6)$ \\
\hline
\end{tabular}

Table 3: Comparison of reliability estimates, full sample and by gender

\begin{tabular}{|l|l|l|l|}
\hline Country & Alpha: Full sample & Alpha: Women & Alpha: Men \\
\hline AUSTRALIA & 0.87 & 0.87 & 0.86 \\
\hline CANADA & 0.87 & 0.88 & 0.86 \\
\hline ENGLAND & 0.88 & 0.88 & 0.84 \\
\hline GERMMAY & 0.87 & 0.86 & 0.86 \\
\hline ICELAND & 0.88 & 0.89 & 0.77 \\
\hline UNITES STATES & 0.86 & 0.85 & 0.81 \\
\hline
\end{tabular}

Table 4: Pearson's correlational coefficients for CFPP, FOBS and DASS-21 subscales

\begin{tabular}{|l|l|l|l|l|}
\hline Country & Depression & Anxiety & Stress & FOB-VAS \\
\hline AUSTRALIA & 0.20 & 0.24 & 0.25 & 0.71 \\
\hline CANADA & 0.20 & 0.23 & 0.26 & 0.77 \\
\hline ENGLAND & 0.22 & 0.27 & 0.26 & 0.74 \\
\hline GERMMANY & 0.18 & 0.28 & 0.25 & 0.64 \\
\hline ICELAND & 0.17 & 0.22 & 0.25 & 0.63 \\
\hline UNITED STATES & 0.25 & 0.27 & 0.31 & 0.68 \\
\hline
\end{tabular}


Table 5: DASS-21, FOBS and CFPP scores, by sample

\begin{tabular}{|l|l|l|l|l|l|l|}
\hline Country & DASS-21 & Depression & Anxiety & Stress & $\begin{array}{l}\text { FOB- } \\
\text { VAS }\end{array}$ & FOBS-PP \\
\hline AUSTRALIA & 12.0 & 3.0 & 3.0 & 6.0 & 56.4 & 36.6 \\
\hline CANADA & 11.0 & 2.0 & 3.0 & 5.0 & 50.4 & 34.3 \\
\hline ENGLAND & 12.0 & 3.0 & 3.0 & 5.0 & 57.7 & 38.5 \\
\hline GERMANY & 4.0 & 1.0 & 1.0 & 2.0 & 45.8 & 29.8 \\
\hline ICELAND & 8.0 & 2.0 & 2.0 & 4.0 & 46.0 & 35.1 \\
\hline USA & 14.0 & 3.0 & 2.0 & 6.0 & 57.0 & 37.0 \\
\hline
\end{tabular}

Note: For the DASS-21 and its subscales, we report median scores (because scores are negatively skewed). For the fear scales we report means. 


\section{References}

1. Zar M, Wijma K, Wijma B. Pre- and Postpartum Fear of Childbirth in Nulliparous and Parous Women. Scand J Behav Ther [Internet]. 2001 Jan;30(2):75-84.

2. Hall W, Hauck YL, Carty EM, Hutton EK, Fenwick J, Stoll K. Childbirth fear, anxiety, fatigue, and sleep deprivation in pregnant women. J Obstet Gynecol Neonatal Nurs [Internet]. 2009 [cited 2014 Mar 13];38(5):567-76. Available from: http://www.ncbi.nlm.nih.gov/pubmed/19883478

3. Toohill J, Fenwick J, Gamble J, Creedy DK. Prevalence of childbirth fear in an Australian sample of pregnant women. BMC Pregnancy Childbirth. 2014;14(275):e1-10.

4. Eriksson C, Westman G, Hamberg K. Experiential factors associated with childbirth-related fear in Swedish women and men: A population based study. J Psychosom Obstet Gynecol [Internet]. 2005 Jan [cited 2014 Mar 13];26(1):63-72. Available from:

http://informahealthcare.com/doi/abs/10.1080/01674820400023275

5. Melender H-L. Experiences of fears associated with pregnancy and childbirth: a study of 329 pregnant women. Birth [Internet]. 2002 Jun;29(2):101-11. Available from: http://www.ncbi.nlm.nih.gov/pubmed/12051188

6. Räisänen S, Lehto S, Nielsen H, Gissler M, Kramer M, Heinonen S. Fear of childbirth in nulliparous and multiparous women: A population-based analysis of all singleton births in Finland in 1997-2010. BJOG. 2014;121(8):965-70.

7. Saisto T, Halmesmäki E. Fear of childbirth: a neglected dilemma. Acta Obstet Gynecol Scand [Internet]. 2003 Mar;82(3):201-8. Available from: http://www.ncbi.nlm.nih.gov/pubmed/12694113

8. Maier BB. Women's worries about childbirth : Making safe choices. BMJ. 2010;18(5):293-300.

9. Johansson M, Rubertsson C, Rådestad I, Hildingsson I. Childbirth - An emotionally demanding experience for fathers. Sexual \& Reproductive Healthcare 3 (2012) 11-20

10. Johansson M, Fenwick J, Premberg A. A meta-synthesis of fathers' experiences of their partner's labour and the birth of their baby.Midwifery. 2015 Jan;31(1):9-18. doi: 10.1016/j.midw.2014.05.005

11. Bergström M, Rudman A, Waldenström U, Kieler H. Fear of childbirth in expectant fathers, subsequent childbirth experience and impact of antenatal education: subanalysis of results from a randomized controlled trial. Acta Obstet 
Gynecol Scand 2013; 92:967-973.

12. Hanson S, Hunter LP, Bormann JR, Sobo EJ. Paternal fears of childbirth: a literature review. J Perinat Educ [Internet]. 2009 Jan [cited 2014 Mar 12];18(4):12-20. Available from:

http://www.pubmedcentral.nih.gov/articlerender.fcgi?artid=2776519\&tool=pmcen trez\&rendertype $=$ abstract

13. Hildingsson I. Swedish couples' attitudes towards birth, childbirth fear and birth preferences and relation to mode of birth: A longitudinal cohort study. Sex Reprod Healthc. 2014;5:75-80.

14. Stoll K, Hall WA. Attitudes and Preferences of Young Women With Low and High Fear of Childbirth. Qualitative Health Research 2013;23(11), 1495-1505.

15. Stoll K, Hall W, Janssen P, Carty E. Why are young Canadians afraid of birth? A survey study of childbirth fear and birth preferences among Canadian University students. Midwifery. 2014;30(2):220-6.

16. Stoll K, Fairbrother N, Carty E, Jordan N, Miceli C, Vostrcil Y, et al. "It's all the rage these days": University students' attitudes toward vaginal and cesarean birth. Birth. 2009;36(2):133-40.

17. Gallagher F, Bell L, Waddell G, Benoit A, Cote N. Requesting cesareans without medical indications: An option being considered by young Canadian women. Birth Issues Perinat Care. 2012;39(1):39-47.

18. Edmonds J, Cwiertniewicz T, Stoll K. A survey of childbirth preferences and attitudes among young women prior to pregnancy. J Perinat Educ. 2015;24(2):93101.

19. Ryding E, Lukasse M, Van Parys A, Wangel A, Karro H, Kristjansdottir H, et al. Fear of childbirth and risk of cesarean delivery: A cohort study in six European countries. Birth. 2015;42(1):48-55.

20. Wijma K, Wijma B, Zar M. Psychometric aspects of the W-DEQ; a new questionnaire for the measurement of fear of childbirth. J Psychosom Obstet Gynecol [Internet]. 1998 Jan [cited 2014 Mar 13];19(2):84-97. Available from: http://informahealthcare.com/doi/abs/10.3109/01674829809048501

21. Laursen M, Hedegaard M, Johansen C. Fear of childbirth: predictors and temporal changes among nulliparous women in the Danish National Birth Cohort. BJOG [Internet]. 2008 Feb [cited 2014 Jan 21];115(3):354-60. Available from: http://www.ncbi.nlm.nih.gov/pubmed/18190372 
22. Hildingsson I, Nilsson C, Karlström A, Lundgren I. A longitudinal survey of childbirth-related fear and associated factors. J Obs Gynecol Neonatal Nurs. 2011;40(5):532-43.

23. Anderson C, Gill M. Childbirth related fears and psychological birth trauma in younger and older age adolescents. Appl Nurs Res. 2014;27(4):242-8.

24. Haines H, Pallant JF, Karlström A, Hildingsson I. Cross-cultural comparison of levels of childbirth-related fear in an Australian and Swedish sample. Midwifery [Internet]. 2011 Aug [cited 2014 Mar 13];27(4):560-7. Available from: http://www.ncbi.nlm.nih.gov/pubmed/20598787

25. Elvander C, Cnattingius S, Kjerulff KH. Birth experience in women with low, intermediate or high levels of fear: findings from the first baby study. Birth [Internet]. 2013 Dec;40(4):289-96. Available from:

http://www.ncbi.nlm.nih.gov/pubmed/24344710

26. Rouhe H, Salmela-Aro K, Halmesmaki E, Saistoa T. Fear of childbirth according to parity, gestational age, and obstetric history. BJOG. 2008;116(1):67-73.

27. Lukasse M, Vangen S, Øian P, Schei B. Fear of childbirth, women's preference for cesarean section and childhood abuse: a longitudinal study. Acta Obstet Gynecol Scand [Internet]. 2011 Jan [cited 2014 Mar 13];90(1):33-40. Available from: http://www.ncbi.nlm.nih.gov/pubmed/21275913

28. Saisto T, Salmela-Aro K, Nurmi JE, Halmesmäki E. Psychosocial characteristics of women and their partners fearing vaginal childbirth. BJOG [Internet]. 2001 May;108(5):492-8. Available from: http://www.ncbi.nlm.nih.gov/pubmed/11368135

29. Laursen M, Johansen C, Hedegaard M. Fear of childbirth and risk for birth complications in nulliparous women in the Danish National Birth Cohort. BJOG [Internet]. 2009 Sep [cited 2014 Jan 23];116(10):1350-5. Available from: http://www.ncbi.nlm.nih.gov/pubmed/19538412

30. Fairbrother N, Woody SR. Fear of childbirth and obstetrical events as predictors of postnatal symptoms of depression and post-traumatic stress disorder. J Psychosom Obstet Gynaecol [Internet]. 2007 Dec [cited 2014 Feb 21];28(4):239-42. Available from: http://www.ncbi.nlm.nih.gov/pubmed/17966050

31. Johnson R, Slade P. Does fear of childbirth during pregnancy predict emergency caesarean section? BJOG [Internet]. 2002 Nov;109(11):1213-21. Available from: http://www.ncbi.nlm.nih.gov/pubmed/12452457 
32. Jokić-Begić N, Zigić L, Nakić Radoš S. Anxiety and anxiety sensitivity as predictors of fear of childbirth: Different patterns for nulliparous and parous women. J Psychosom Obs Gynaecol. 2014;35(1):22-8.

33. Ingimarsson B. Próffræðilegt mat á DASS sjálfsmatskvarðanum. Punglyndi, kvíði og streita [Psychometric evaluation of the DASS scale. Depression, anxiety and stress] [Internet]. 2010 p. e1-67. Available from: http://skemman.is/stream/get/1946/5411/16254/1/Björgvin_Ingimarsson__DASS.pdf

34. Nilges P, Essau C. Die Depressions-Angst-Stress-Skalen. Der DASS - ein Screeningverfahren nicht nur für Schmerzpatienten. (The DASS, a screening procedure not only for pain patients]. Der Schmerz, Published online July 2015.

35. Maneesriwongul W, Dixon J. Instrument translation process: A methods review. J Adv Nurs. 2004;48(2):175-86.

36. Bland J, Altman D. Statistics notes: Cronbach’s alpha. BMJ. 1997;314:275.

37. Roberts A. Evidence -based practice manual: Research and outcome measures in health. Ohio: Ohio State University Medical Center; 2004.

38. DeVellis R. Scale development: theory and applications: Theory and application. California: Sage; 2012.

39. Hildingsson I, Johansson M, Fenwick J, Haines H, Rubertsson C. Childbirth fear in expectant fathers: Findings from a regional Swedish cohort study. Midwifery [Internet]. Elsevier; 2013 Feb 27 [cited 2014 Feb 12];1-6. Available from: http://www.ncbi.nlm.nih.gov/pubmed/23455031

40. Lovibond S, Lovibond P. Manual for the Depression Anxiety Stress Scales (2nd. Ed.). Psychology Foundation; 1995.

41. Antony M, Bieling P, Cox B, Enns M, Swinson R. Psychometric properties of the 42-item and 21-item versions of the Depression Anxiety Stress Scales (DASS) in clinical groups and a community sample. Psychol Assess. 1998;10:176-81.

42. Henry J, Crawford J. The 21-item version of the Depression Anxiety Stress Scales (DASS-21): Normative data and psychometric evaluation in a large non-clinical sample. Br J Clin Psychol. 2005;44(227-239).

43. Sheng, $\mathrm{Y}$, Sheng, Z. Is Coefficiant Alpha rebost to non-normal data? Front Psychol. 2012; 3:34.

44. Storksen H, Eberhard-Gran M, Garthus-Niegel S, Eskild A. Fear of childbirth: The relation to anxiety and depression. Acta Obstet Gynecol Scand. 2012;91:237-42. 
45. Nerum H, Halvorsen L, Sørlie T, Oian P. Maternal request for cesarean section due to fear of birth: can it be changed through crisis-oriented counseling? Birth [Internet]. 2006 Sep;33(3):221-8. Available from:

http://www.ncbi.nlm.nih.gov/pubmed/16948722

46. Ryding E, Wijma B, Wijma K, Rydhström H. Fear of childbirth during pregnancy may increase the risk of caesarean section. Acta Obstet Gynecol Scand. 1998;77:542-7.

47. Stoll K, Hall W. Vicarious Birth Experiences and Childbirth Fear: Does It Matter How Young Canadian Women Learn About Birth? J Perinat Educ [Internet]. 2013 Jan 1;22(4):226-33. Available from:

http://openurl.ingenta.com/content/xref?genre=article\&issn=1058$1243 \&$ volume $=22 \&$ issue $=4 \&$ spage $=226$

48. Stoll K, Edmonds J, Hall W. Fear of childbirth and preference for cesarean section among young American women prior to childbirth: A survey study. Birth. 2015;in press. 